\title{
O FORTALECIMENTO DA POLÍTICA EXTERNA CHINO-BRASILEIRA NOS ÚLTIMOS io ANOS
}

\author{
Wallace Moacir Paiva Lima ${ }^{1}$
}

RESUMO: O objetivo do trabalho é analisar através de revisão bibliográfica sobre o fortalecimento da política externa chino brasileira nos últimos io anos. No próximo ano, a República Popular da China (RPC) está em vias de aumentar significativamente sua presença comercial no Brasil. Essa possibilidade reflete o atual interesse estratégico da China no Brasil, uma vez que os dois países trabalham juntos para criar uma vacina contra a COVID-Ig. Se bem-sucedida, uma vacina aliviaria grande parte das atuais preocupações econômicas e de saúde pública em ambos os países, já que a recuperação da pandemia abriria oportunidades de comércio e incentivaria maiores laços comerciais em todos os níveis entre a RPC e o Brasil O tipo do estudo é uma revisão bibliográfica, pesquisas do tipo tem o objetivo primordial à exposição dos atributos de determinado fenômeno ou afirmação entre suas variáveis.

Palavras-chave: China. Brasil. Política externa.

\section{INTRODUÇÃO}

No próximo ano, a República Popular da China (RPC) está em vias de aumentar significativamente sua presença comercial no Brasil. Essa possibilidade reflete o atual interesse estratégico da China no Brasil, uma vez que os dois países trabalham juntos para criar uma vacina contra a COVID-I9. Se bem-sucedida, uma vacina aliviaria grande parte das atuais preocupações econômicas e de saúde pública em ambos os países, já que a recuperação da pandemia abriria oportunidades de comércio e incentivaria maiores laços comerciais em todos os níveis entre a RPC e o Brasil (ALBUQUERQUE, 2020).

O Brasil foi o primeiro país na região que a RPC reconheceu como um "Parceiro Estratégico”, com a China concedendo esse status ao Brasil em 1993, depois elevando o status do Brasil para "Parceiro Estratégico Abrangente" em 2012. Em termos econômicos, o

\footnotetext{
${ }^{1}$ Bacharel em Ciências Políticas e Relações Internacionais pelo Centro Universitário Internacional do Paraná (UNINTER).E-mail:.wmpaivalima@gmail.com.
} 
Brasil recebeu U\$\$ 55 bilhões em investimentos chineses em 145 projetos na última década, representando quase metade dos US \$ 123 bilhões investidos por empresas sediadas na RPC na região. Desde 2005, os dois principais bancos de políticas da China emprestaram ao Brasil U\$ 28,9 bilhões, mais do que qualquer outro país, exceto à Venezuela, e representando mais de 21\% dos U\$ 137 bilhões emprestados à América Latina naquela época. (ALVARENGA, et al, 2020)

O alinhamento do presidente brasileiro Jair Bolsonaro com o governo Trump e as recentes trocas negativas entre a RPC e o Brasil dão uma impressão enganosa de uma ruptura duradoura entre o Brasil e a China. De fato, embora o investimento no Brasil por empresas sediadas na RPC tenha caído para um mínimo de $\$ 284$ milhões em 2018, os investimentos por empresas sediadas na RPC no Brasil se recuperaram para robustos \$ I,8 bilhão em 2019. No final de 2019, o governo chinês indicou que tinha US \$ roo bilhões para investir no Brasilem cinco fundos governamentais diferentes (CHAGAS-BASTOS, 2019).

O objetivo do trabalho é analisar através de revisão bibliográfica sobre o fortalecimento da política externa chino brasileira nos últimos ı anos.

O tipo do estudo é uma revisão bibliográfica, pesquisas do tipo tem o objetivo primordial à exposição dos atributos de determinado fenômeno ou afirmação entre suas variáveis. Assim, recomenda-se que apresente características do tipo: analisar a atmosfera como fonte direta dos dados e o pesquisador como um instrumento interruptor; não agenciar o uso de artifícios e métodos estatísticos, tendo como apreensão maior a interpretação de fenômenos e a imputação de resultados, o método deve ser o foco principal para a abordagem e não o resultado ou o fruto, a apreciação dos dados deve ser atingida de forma intuitiva e indutivamente através do pesquisador.

\section{FORTALECIMENTO DA POLÍTICA EXTERNA CHINO BRASILEIRA}

Mesmo antes das atuais tensões entre China e Brasil, o interesse econômico do presidente Bolsonaro na RPC era um poderoso contrapeso contra seu ceticismo público em relação ao país. Bolsonaro visitou a RPC cinco meses após a visita positiva do vice-presidente brasileiro, Hamilton Mourão, em maio de 2019. Durante sua visita, o presidente Bolsonaro moderou significativamente sua retórica anti- China anterior, proclamando que Brasile 
China compartilhavam um objetivo comume procuravam atrair investimentos da RPCe cooperação em tecnologia. Um mês depois, em novembro de 2019, o presidente deu as boasvindas ao seu homólogo Xi Jinping em Brasília para a cúpula do BRICS, proclamando que “a China é uma parte cada vez maior do futuro do Brasil” (LACERDA, 2019).

A expansão do papel da China e da importância econômica para o Brasil, apesar do ceticismo inicial de Bolsonaro, parece determinada a se manifestar à medida que entidades chinesas compram produtos brasileiros agrícolas, de mineração e de petróleo; investir e emprestar fundos; adquirir ativos em dificuldades em setores estrategicamente valiosos em todo o país; e a necessidade do Brasil de investimento chinês em projetos de infra-estrutura de transporte, eletricidade e telecomunicações, bem como a atividade geradora de empregos associada no país (SANTOS; ALBUQUERQUE, 2020).

Mesmo com a atividade econômica chinesa prejudicada pela pandemia, a RPC ainda comprou 34\% dos US \$ 121,3 bilhões em exportações do Brasil entre janeiro e julho de 2020. Os EUA, em comparação, compraram menos de $15 \%$ dessas exportações. Graças em parte à forte demanda da China por produtos agrícolas, suas importações do Brasil aumentaram ı\% durante o mesmo período. A demanda da RPC por exportações brasileiras é ampliada quando se considera o desempenho econômico lento esperado de outros parceiros econômicos do Brasil, incluindo a Argentina, com uma queda projetada de I0,5\% no PIB para 2020 , os Estados Unidos, cujo PIB deve contrair 4,9\%e a União Européia, cujo PIB coletivo deve encolher $8,7 \%$ durante o período (LACERDA, 2019).

Em meio a alternativas reduzidas, a demanda chinesa por agricultura, mineração e petróleo provavelmente será uma tábua de salvação para o Brasil. Atualmente, $46 \%$ das exportações agrícolas do Brasil vão para a RPC. As exportações de soja do Brasil devem atingir níveis recordes em 2020 e aumentar 9,1\% em relação ao ano anterior. 31 por cento das exportações de açúcar do Brasilvão para a China, com um aumento particularmente grande depois que a RPC concordou em maio de $2020 \mathrm{em}$ reduzir as tarifas sobre o açúcar brasileiro. A China também demonstrou um apetite crescente por grandes quantidades de produtos brasileiros que a RPC não importava anteriormente, como café, melão e outras frutas (ALBUQUERQUE, 2020). 
Talvez o maior prêmio potencial para os produtores agrícolas brasileiros seja a carne. O surto de peste suína na China em maio de 2019 criou uma oportunidade para os produtores brasileiros ampliarem sua participação no mercado. Atualmente, 45 frigoríficos brasileiros estão autorizados a exportar para a RPC e, apesar da pandemia, a demanda chinesa deve manter as exportações de frangodo Brasilestáveisem 2020. No entanto, o COVID-ig também criou desafios no setor, com seis frigoríficos brasileiros impedidos de exportar para a China depois que o COVID-ı foi detectado em seus frangos (SANTOS; ALBUQUERQUE, 2020).

A atenção do governo brasileiro para a RPC provavelmente será reforçada pelas nomeações para o gabinete do presidente. Entre eles está a recente nomeação de Roberto Fendt como vice-ministro da Economia, com responsabilidade por Comércio Exterior e Assuntos Internacionais. Fendt foi ex-secretário executivo do Conselho Empresarial ChinaBrasil, o principal órgão do país para promover o comércio e os investimentos com a RPC.Fendt cumprimentará outros altos funcionários do governo de Bolsonaro que estão otimistas com a China, incluindo o já mencionado vice-presidente Hamilton Mourão, cuja visita de maio de 2019 à RPC foi particularmente notável pelo tom extremamente positivo do vice-presidente em relação à China, elogiando-a como "global liderança"e boas-vindas a mais investimentos de empresas chinesas.

No âmbito federal, o avanço do comércio e dos projetos chineses no país será ainda mais impulsionado pelo COSBAN, comitê binacional de nível ministerial constituído como parte da parceria estratégica Brasil-China para facilitar a cooperação, mas cuja utilização tem variado em diferentes administrações brasileiras. Durante a visita de Estado do Presidente $\mathrm{Xi}$ ao Brasil em dezembro de 2019, os dois governos concordaram em usar o COSBAN como um veículo-chave de coordenação (LACERDA, 2019).

Apesar das oportunidades para avanços chineses em várias frentes, as preocupações do presidente Bolsonaro e seu governo com a China, reforçadas pelos EUA, provavelmente retardarão a aprovação de aquisições e a adjudicação de grandes projetos de infra-estrutura a empresas chinesas. Essas preocupações podem afetar particularmente áreas como a escolha do Brasil de construir uma rede de telecomunicações $5 \mathrm{G}$, com o Brasil já inicialmente programado para 2020, até 2021 ou mais tarde (ALBUQUERQUE, 2020). 
À medida que o envolvimento da RPC com o Brasil decola no ambiente pósCOVID-I9, as empresas chinesas já estão presentes e estão posicionadas para fazer avanços significativos em quase todos os setores. As características desse avanço, seja por meio de fusões e aquisições, projetos Greenfield ou expansão incremental de projetos existentes, o tamanho e sofisticação das empresas chinesas envolvidas, e sua relação com os parceiros locais, serão diferentes de acordo com o setor e a posição das empresas chinesas estabeleceu (LACERDA, 2019).

O acesso ao petróleo do Brasil e às tecnologias para obtê-lo, como exploração e perfuração em águas profundas, há muito tempo é do interesse de bancos e investidores sediados na RPC. Oempréstimo de U\$\$ Io bilhõesda China à Petrobras em 2009 foi fundamental para seu avanço no setor, possivelmente abrindo caminho para a compra de US \$3,I bilhões da Sinochem em maio de zoro das participações brasileiras da empresa norueguesa Statoil; Injeção de U\$ 7,I bilhões da Sinopec nas operações da espanhola Repsol no Brasil no mesmo ano; a compra de US \$5,2 bilhões de uma participação de 30 por cento na petrolífera Galp em 20II; e a compra da Sinochem em 2012 de uma participação de ro por cento nas operações brasileiras da Perenco. Cada um desses avanços na presença de petróleo da China no Brasil, em última análise, pavimentou o caminho para o primeiro grande investimento da China em exploração e desenvolvimento no ambiente de águas profundas do Brasil (ALBUQUERQUE, 2020).

As empresas da RPC têm desempenhado um papel significativo como cliente e investidor nas indústrias de mineração brasileiras. Em agosto de 2020, apesar dos efeitos negativos da COVID-ı9 nas exportações globais em geral, a VALE cogitava investir em instalações paraexpandir sua produçãopara acomodar a crescente demanda chinesa, incluindo uma joint venture no Pará, com a chinesa Concremat, para em conjunto construir uma usina de aços planos de $\$ 370$ milhões (ALBUQUERQUE, 2020).

A Sul Americana de Metais, adquirida pela empresa de Hong Kong Honbridge Holdings em 2010, estava considerando um novo investimento no complexo de mineração de \$2,2 bilhõesem Minas Gerais em setembro de 2019. As empresas chinesas também se posicionaram na mineração de metais de terras raras no Brasil, uma das os poucos países fora da China onde esses metais estão concentrados. Em 20II, o grupo chinês Baosteel 
comprou uma participação de Is por cento na mineradora de metais de terras raras CBMM (LACERDA, 2019).

Como na mineração, as empresas sediadas na RPC têm buscado fazer a transição da compra de produtos agrícolas brasileiros para a cadeia de valor que os produz. As primeiras tentativas, no entanto, comobuscar a compra de terras agrícolas brasileiras econstruir operações de agronegócio em concorrência com empresas internacionais estabelecidas no setor, como ADM, Bunge, Cargill e Dreyfus, foram em grande parte malsucedidas . Exemplos notáveis de projetos fracassados incluem uma instalação de agronegócio de US \$ 2 bilhões da Chongqing Grain na Bahia, que nunca foi realizada (ALBUQUERQUE, 2020).

As empresas da RPC têm tido mais sucesso ao usar seu capital para adquirir empresas com ativos de agronegócio pré-existentes e tecnologias de interesse, canalizando a demanda chinesa para favorecer as empresas adquiridas. As compras chinesas notáveis a este respeito incluem as aquisições de 2014 da HK Noblee daNiderapela China Oil and Foodstuffs Corporation (COFCO).

A grande população brasileira e o mercado consumidor associado, e seu acesso a outros mercados por meio de sua adesão ao Mercosul, há muito atraem empresas chinesas. As políticas industriais do país, com altos impostos para produtos acabados importados, obrigaram as empresas sediadas na RPC a localizar várias partes de suas operações de montagem final dentro do país em uma variedade de setores, de automóveis, caminhões e ônibus a trens elétricos e fabricação de painéis solares .

No setor automotivo, as empresas chinesas JAC, Chery, Chang'an, Shineray, Foton e outras estabeleceram instalações de montagem final no país. Apesar da pandemia, em agosto de 2020, a Chery Brasil anunciou planos de expandir suas operações no Brasil para produzir seu modelo Tiggo-8 em sua fábrica em Anápolis, Goiás (LACERDA, 2019).

\section{CONCLUSÃO}

Como a disponibilidade de uma vacina e outras medidas permitem que o Brasil ultrapasse a atual crise econômica e de saúde, a RPC e suas empresas estão posicionadas para fazer avanços comerciais e políticos significativos no país. COVID-ı9 desviou a atenção de, e temporariamente desacelerou, o envolvimento em expansão da China com o Brasil, mas 
também ampliou a necessidade socioeconômica de serviços que as empresas chinesas estão bem posicionadas para fornecer e alavancar.

Embora o envolvimento com a RPC como um parceiro econômico dinâmico e rico em recursos não seja inerentemente ruim, o Brasil e outros países do hemisfério devem estar atentos aos compromissos predatórios que alavancam a necessidade de concretizar relações econômicas e políticas que não duram muito -interesse de prazo pelo desenvolvimento econômico, democracia e independência do país.

\section{REFERÊNCIAS BIBLIOGRÁFICAS}

ALBUQUERQUE, M. (2020). 'Globalização da saúde pública: a Organização Mundial da Saúde e a cooperação na América do Sul', Boletim OPSA, n. 2, pp. 7-ı6.

AlvarengA, A. A. ROCHA, E.M.S. FillipON, J. ANDRADE, M. A. C. (2020). 'Desafios do estado brasileiro frente à pandemia pela covid-rg: o caso da paradiplomacia maranhense', Cadernos de Saúde Pública, 36 (I2), I5p.

CHAGAS-BASTOS, F. H. (2019). 'Political realignment in Brazil: Jair Bolsonaro and the right turn', Revista de Estudios Sociales, v. 69, pp. 92-1oo.

LACERDA, M. B. (2019) O novo conservadorismo brasileiro: de Reagan a Bolsonaro. Porto Alegre: Zouk.

SANTOS, L. W.; ALBUQUERQUE, M. (2020). 'A pandemia de Covid-r9 nas políticas doméstica e externa do Brasil: disputa entre poderes institucionais, alinhamento aos EUA e isolamento internacional'. Boletim OPSA, n. 2, pp. 7-16. 